\title{
Investigation of Chinese Students' Passive Learning in EAP Classroom
}

\begin{abstract}
CHEN Yi
Shanghai Ocean University, Shanghai, China

Unlike in other countries where students come from multilingual background, Chinese EAP (English for Academic Purposes) students are quieter than those in intercultural settings, which bring "inflated" problems for Chinese teachers of EAP. With the rocketing amount of students who study abroad each year, the problems have commenced to spread over to other EAP settings in numerous English speaking countries, triggering continual laments from lecturers globally. Therefore, as an EAP teacher in China with six year experience, the author reflects potential causes of such reticence within the classroom and possible approaches to convert passive learning behavior into a proactive one. The presentation discusses the rationale of the passive learning in Chinese classrooms, and its linguistic, cultural, and sociological interpretations of the predicaments, all based on a questionnaire and interviews done within the Shanghai Ocean University. Further analysis presents data collected from the respondents in university EAP classes. Furthermore, a set of solutions for necessary innovations of the teaching and learning is provided and analyzed. Finally, an emphasis is placed on examining the construction of EAP teachers' rapport with students and ways to reinforce teacher-student relationship in the EAP settings, which was overlooked by EAP professionals both in China and abroad in decades. With better understanding, "mute" classes may cease to exist sooner or later. Illustrations of diversified activities that aim to help learners transform their learning patterns and EAP teachers adopt new practices in their own institutes are testified in the presentation. Kongzi (known as Confucius), once asserted: "involve me and I will understand", which can, undeniably, justify the idea that Chinese students may have not behaved as passive learners in history and that "involvement" implies engagement rather than quiescence.
\end{abstract}

Keywords: reticence, tele-interviewing project, OEC, "Shidao"

\section{Introduction}

China's economic growth has astonished the world with an annual dramatic increment of GDP; unlike its economic achievement, the outside world seems to pay less attention to the Chinese students' perplexities which, to a certain degree, have impeded both teaching and learning domestically and globally. Over the last five to seven years, the amount of Chinese students who chose to study in UK, USA, or other Western societies have rocketed up to an unprecedented high figure, so have they brought "inflated" quandaries in the classrooms of the target states. Therefore, not only Chinese local teachers, but the lecturers abroad have a number of grievances towards Chinese learners, who "tended to be extremely reticent than other international undergraduates" (LI \& JIA, 2006, p. 198), who are, in like manner, well-known for absorbing knowledge than

CHEN Yi, EAP lecturer, M.A., AIEN Institute, Shanghai Ocean University. E-mail: y-chen@shou.edu.cn. 
actively participating in the classrooms (ibid., 2006). Stereotypical comments are occasionally heard, for example, Chinese learners incline to be "particularly passive and quieter" than other Western students (CHEN, 1985; FENG, 1991; Upton, 1989, as cited in HUANG \& Cowden, 2009) possibly due to their incompetent linguistic proficiency; it is generally true though. On the other hand, they are, as well, glorified as awfully intelligent and assiduous other than lack of creativity. After all, what, in reality, are Chinese learners like?

The paper aims to investigate the passivity of Chinese EAP learners and how it has been formed in regards to sociocultural, linguistic competence and pedagogical factors. Moreover, detailed solutions will be recommended in order to convert the passive EAP learners to active ones with introducing several innovative methods. Finally, the paper will discuss an "uncaring" issue that is the special rapport developed between students and teachers in the Chinese EAP setting (mono-cultural background rather than multi-cultural one), and why it should not be overlooked by expatriate lecturers in China, in particular, to those who will teach EAP or ESP course in Chinese universities.

In AIEN Institute of Shanghai Ocean University, there are 12 expatriate lecturers who come from 11 different countries (UK, USA, Australia, Ireland, New Zealand, Nigeria, India, Canada, Bulgaria, Philippines, and China). The teaching staff is purely international and they have brought our undergraduates with diverse cultures of almost all continents. In contrast, our students' composition is solely mono-cultural, mainly consisting of the Han majority with approximately 10 Uyghur minority undergraduates. Therefore, the paper also attempts to explain the cultural conflicts that exist and how our expatriate lecturers explore approaches to settle the existing problems in our EAP classes.

In EAP classrooms in my university, several lecturers have experienced a similar situation in which reticent Chinese learners sat there passively without responding to the lecturers who claimed that the embarrassment has greatly impacted their mood in teaching. According to the lecturers in my university, "reticence, vegetating, disrespect, and resistance" are four words that appear to be predominantly recurring remarks in an EAP setting. A number of "inexperienced" EAP lecturers work under pressure and feel frustrated while tackling the circumstances. Meanwhile, these words have likewise puzzled them for a long time that they often interrogate - why did the similar materials or methodology result in a totally disparate outcome? In our case, one group may perform extremely distinctive whereas others can be totally disastrous. If excellence is what most lecturers expect, subsequently, what are the causes that lead to the passivity and mediocrity?

\section{Methodology}

SOJUMP is a very popular and effective online survey website which provides all sorts of investigations for various purposes. Firstly, a set of questionnaires were made and uploaded to our students of 2013 cohort and 2014 cohort approximately 300 in total as well as to approximately 50 students in other faculties. Six questions were designed in order to find out the fundamental cause of passive learners and their attitude in regarding to further behavioral changes. In about two weeks, SOJUMP collected more than $85 \%$ valid answers, so its result manifests that four essential circumstances are observed, which can be classified as cultural, social impacts, previous educational experience, together with family influence that appears to be noticeable factors (SOJUMP, 2014). The passive learning in a Chinese EAP setting may contribute to cultural, social, and educational grounds. 


\section{Reasons for the Passivity (Mientzu: Face and Quanwei: Authority as the Major Factors)}

Over 30\% respondents consider that passive learning behavior is related to the cultural background where one subsists and this is especially accurate in China. There is a solid evidence to demonstrate that "face" saving is a vital issue for a great number of Chinese including learners, who forcefully presume that losing face will produce an awful personal image, therefore, blushing or flushing face in a classroom is not odd. As a matter of fact, this is an indication of shyness or passivity. The survey reveals that $60 \%$ undergraduates (see as per Table 5 in Appendix) are afraid of making mistakes, which suggests that protecting one's face is their priority both in and out of classrooms, and this has been affirmed by Ho and Crookall (1995) alleging that Chinese are preoccupied with "mientzu" (face) which must be protected in public.

Challenging authority is a distinct taboo in Chinese classrooms, which implies that authority such as teachers, according to HUANG and Cowden (2009), who are expected to practice authority, hence, not allowed to be challenged in any case. To challenge peers in various cases is not momentous, not mentioning the senior citizens under whatsoever circumstance. Moreover, remaining low profile is stereotypically regarded as an excellent example of being an admirable citizen. This is proven by manifold cultural phenomena shown in proverbs literally translated as "silence is gold", "disagreeing is not obligatory", and "obeying is a morally accepted virtue". If one violates those ethical virtues, he will confront hardship in communicating effectively with their peers.

\section{Social Norms That Deteriorate the Situation of Being a Passive Learner}

Passivity or reticence conjointly arises from social factors which can be partially attributed to China's collectivism social norms. In a collectivist society, one coexists with other peers who frequently interject pressure towards each other. Over 30\% learners, for instance, reckon that their rapport must be reinforced through treating each other delightfully rather than interjecting pressure towards one another. In contrast, if one outperforms others, he is regarded as "alienated" from the group, therefore, will be guffawed habitually and frequently. Such subtle relationship is carefully upheld during their learning process. Another significant certitude is the peer rapport which is sustained through certain tacit rules under which one is not obviously presenting that he tends to be ostentatious in any circumstances (shown in the chart that 43 students expressed that they do not aspire to flaunt in the classroom while only two students believe that it has nothing to do with showing off). Another unspoken rule is that asking questions in Chinese education settings is not appropriate. As a result, students incline to approach you and ask questions when classes terminate, which puzzles plentiful Western teachers who tend not to be bothered while working in China in their leisure time.

In terms of education impacts, rote learning, teacher-centered methodology, and test-oriented educational system are among the blames. With at least 12 years of being shaped as a reticent or passive learner under a rotten educational organization, a large number of Chinese learners involve themselves in a circle of mechanical reciting or known as "rote" learning, and they are away from "critical" thinking development and transferable skills input. The philosophy of rote learning is misinterpreted by modern Chinese scholars who stereo-typically estimate that our ancient educational ideology which, as a matter of fact, "encouraged learners in interactions in learning" (NAN, 2007, pp. 199-200) rather than passively absorbing knowledge. As NAN (2007) further explicates, Mandarin character “学问” (xuewen) entails both "learning and enquiry" in a long-term process which requires learners to be vigorous in obtaining knowledge throughout their life. 


\section{The Solutions That Work Especially for the Chinese EAP Passive Learners}

Culturally, socially as well as educationally, the issue emerged to be clearer to us with sufficient evidences to demonstrate how and why learners in China behave in such a manner (reticence or passivity pattern in classrooms). In my past experience, solutions have been sought after with loads of experiments in our EAP classrooms. A number of them had really great outcomes.

However, discrepancy exists when referring to solutions for a significant conversion which may possibly bring impacts on transforming undergraduates to active learners, and the only common ground which both teachers and learners agreed on was the group work that possibly leads to positive outcomes of learning and teaching. Learners appeared to be more positive towards the change while teachers reacted more passively in this transitional period when they insisted on lecturing or preaching to which they were used over their past experience. This is definitely not appropriate as a teacher to apply preaching in 21 st century EAP classrooms. Instead of putting ourselves in wrong circumstances, our teaching staff in AIEN made an attempt in adopting the collaborative learning methodology which massively engages students in task-based learning. Our solutions are based on collaborative learning paradigm that can lead to an augmented ecosystem for the proactive learning.

One major dimension of our innovation in teaching is to apply group works with diversified tasks such as seminar discussion, pair work, debate, and role playing that constrain the learning exceedingly more interactive than ever before. One collaborative task that has been employed is a peer editing assignment in giving feedback on students' writing, which provides learners with supplementary chances in giving feedback to their peers in respect to the writing assignments. According to CHEN (2003), instructors, who act as moderators, should guide the class to engage in various interactions and participation. In reality, our undergrads admit that they have learnt more than ever in assisting editing each others' writing assignment especially under anonymous situations.

Most significantly, an experiment was launched to provide undergrads with additional opportunities to walk out of classrooms with other realistic practices in society. These experiments with strong OEC (Outdoor English Classes) features include simulated seminars, inter-class debates and tele-interviewing projects. In particular, the tele-interviewing was tremendously hailed by both students from Argentina and China, and this task-based project originated in China and cooperated with the National University of Southern Argentina. The interviewing activity involves an extensive number of undergrads who used to be passive and reticent, were being transformed to extensively active participants to carry out various tasks, namely coming up with different questions concerning two countries such as what food people eat, or what activities people appreciate to participate in their spare time, and so on. As a result, learners necessitate preparing what to ask and how to ask the target students in Argentina and vice versa. This has brought up with a mixture of initiative moves towards a regular goal in bringing team members in the group work. Moreover, students from both sides commit to impress efforts to understand each other due to accent confusions from both countries. Finally, learners are motivated to become skilled at different cultural norms and endeavor to immerse themselves in the target culture which inserted much influence on one another's learning.

The suggested solutions on task-based projects strengthen learners with the following skills which they demand in their future career development. They include: 
- Independent study skills;

- Collaborative and interdependent ability;

- Creativity and critical thinking development;

- Problem solving skills (negotiation, compromising);

- Cross-cultural awareness (mutual understandings, conflicts settlement);

- Building confidence (verbal and non-verbal).

In China, creative and critical thinking are insufficiently trained throughout the tertiary education system, and thereupon give rise to inability of problem-solving skills which were deprived for a long period of time among the students who are lacking such competency. According to our past experience, undergrads in China, in like manner, lack cultural interactions with international students and this has brought about numerous cultural confrontations in the international communications, particularly shown in the internship in USA or Australia every summer organized by AIEN Institute while sophomore or juniors are being sent out of China to overseas destinations. If these skills are reinforced in our daily teaching, these students, on the other land, would not embrace various types of cultural conflicts which may prevent undergrads from being more sophisticated in the internship projects.

\section{"Shidao", a New Type of Teacher-Student Rapport Construction}

In addition to the above solutions and analysis of the predicaments, there is a neglected field of our teaching that is the maintenance of the teacher-students rapport. In Chinese culture, this special relationship was tagged as "Shidao" (dignity of teaching). It could be interpreted, as NAN (2007) explicates, "one day's teacher will act as disciples' permanent father" (pp. 328-329). As the society evolves, permanent father image may not be suitable for the things they are. The implication, nonetheless, is that teachers should make friends with their students when they start teaching in a new semester specifically. There are always two scenarios of upholding the relationship, one of which is a pleasant rapport which is being strengthened through both efforts such as English corners, workshops, and office hours supports in which learners regard their teachers as their friends while teachers treat them like "kith and kin". On the contrary, if teachers" face is cold and their attitude may be indifferent, their students will not buy their apathy, and therefore inclining to coldness and passivity. This, hence, forms a vicious circle of teaching and learning which hampers the construction of such rapport.

\section{Conclusion}

To conclude, PRL (passive role in learning) is not merely Chinese learners' patent as described in the survey, the causes are more than what have been analyzed. Chinese students are, customarily, regarded as passive and reticent in classrooms, its cultural and social impacts prevail in our daily teaching. EAP professionals from China together with other nations cooperate under the identical environment to cope with reticent learners. The findings suggest that Chinese learners, although they are constantly paradoxical in behaviors, are basically flexible for the change if a fruitful soil is provided for the transformation. Furthermore, undergrads are genuinely optimistic to predict that they will expect the positive transformation in the near future with those newly introduced approaches (simulations, tele-interviewing, inter-class debate, etc.).

Finally, the finding of students-teacher rapport recommends that teaching will not be successful until teachers befriend their students rather than estrange them in China's educational context. Frankly speaking, there are limitations of my research for PRL this time for the conference. With the increasing interactions 
between Europe and China, understanding Chinese learners and their classroom behaviors may become my additional job other than teaching. By the time of completing this paper, several video conferences have already been held between China and Czech, and we expect that this type of cooperation will benefit the majority of our former "reticent" undergrads who strongly wish to improve their language skills through cross-culture communications.

\section{References}

CHEN, T. (1985). Cultural difference in classrooms: A comparison of Chinese and US schooling (Unpublished manuscript).

CHEN, T. (2003). Reticence in class and online: Two ESL students experience with CLT. Retrieved from $\mathrm{http}: / / \mathrm{www}$. elsevier.com/locate/system

FENG, J. H. (1991). The adaption of students from the People's Republic of China to an American Academic Culture. (ERIC Document Reproduction Service No. ED 329833)

Ho, J., \& Crookall, D. (1995). Breaking with Chinese cultural traditions: Learner autonomy in English language teaching. Retrieved from http://www.people.exeter.ac.uk

HUANG, J. Y., \& Cowden, P. A. (2009). Are Chinese students really quiet, passive and surface learners? -A cultural studies perspective. Canadian and International Education, 38, 78-80.

LI, X. S., \& JIA, X. R. (2006). Why don't you speak up? Eastern Asian students' participation patterns in American and Chinese ESL classrooms. Intercultural Communication Studies, XV, 194-205.

LIU, N. F., \& Littlewood, W. (1997). Why do many students appear reluctant to participate in classroom learning discourse? System, 25(3), 371-384. Retrieved from http://www.sciencedirect.com/science/article/pii/S0346251X97000298

NAN, H. J. (2007). The selection of Nan Hanjin (Vol. 1, pp. 199-200). Shanghai: Fudan Press.

NAN, H. J. (2007). The selection of Nan Huaijin (Vol. 6, pp. 313-337). Shanghai: Fudan Press.

SOJUMP. (2014). Are you a passive learner? Retrieved from http://www.sojump.com/report/4069698.aspx?qc=

Upton, T. A. (1989). Chinese students, American universities, and cultural confrontation. Minne TESOL Journal, 7, 9-28.

\section{Appendix}

Table 1

What is the Main Factor Which Results in Passivity? (SOJUMP, 2014)

\begin{tabular}{lllllll}
\hline $\mathrm{X} / \mathrm{Y}$ & $\begin{array}{l}\text { Family } \\
\text { background }\end{array}$ & Cultural impact & Peer pressure & Previous education exp. & Nil & Total \\
\hline $\begin{array}{l}\text { Shanghai Ocean } \\
\text { University }\end{array}$ & $29(10.14 \%)$ & $73(25.52 \%)$ & $89(31.12 \%)$ & $93(32.52 \%)$ & $2(0.70 \%)$ & 286 \\
$\begin{array}{l}\text { University of } \\
\text { Tasmania }\end{array}$ & $0(0.00 \%)$ & $5(35.71 \%)$ & $3(21.43 \%)$ & $6(42.86 \%)$ & $0(0.00 \%)$ & 14 \\
Other universities $4(11.76 \%)$ & $7(20.59 \%)$ & $14(41.18 \%)$ & $8(23.53 \%)$ & $1(2.94 \%)$ & 34 \\
\hline
\end{tabular}

Table 2

Which of the Following Do You Think True to Describe Your Passive Behavior in Classroom? (SOJUMP, 2014)

\begin{tabular}{llllllll}
\hline $\mathrm{X} / \mathrm{Y}$ & $\begin{array}{l}\text { Teaching is } \\
\text { boring }\end{array}$ & $\begin{array}{l}\text { Materials are } \\
\text { boring }\end{array}$ & $\begin{array}{l}\text { Lack of } \\
\text { peer-peer } \\
\text { interactions }\end{array}$ & $\begin{array}{l}\text { Afraid of } \\
\text { teachers }\end{array}$ & $\begin{array}{l}\text { Afraid of } \\
\text { making } \\
\text { mistakes }\end{array}$ & Nil & Total \\
\hline SHOU & $32(11.19 \%)$ & $41(14.34 \%)$ & $66(23.08 \%)$ & $3(1.05 \%)$ & $144(50.35 \%)$ & $0(0.00 \%)$ & 286 \\
UTAS & $1(7.14 \%)$ & $4(28.57 \%)$ & $6(42.86 \%)$ & $0(0.00 \%)$ & $3(21.43 \%)$ & $0(0.00 \%)$ & 14 \\
Other & $11(32.35 \%)$ & $7(20.59 \%)$ & $5(14.71 \%)$ & $1(2.94 \%)$ & $9(26.47 \%)$ & $1(2.94 \%)$ & 34 \\
\hline
\end{tabular}


Table 3

Do You Think Being Passive in Class in a Negative Trace? (SOJUMP, 2014)

\begin{tabular}{llllll}
\hline X/Y & Yes & No & Maybe & Nil & Total \\
\hline SHOU & $139(48.60 \%)$ & $63(22.03 \%)$ & $84(29.37 \%)$ & $0(0.00 \%)$ & 286 \\
UTAS & $7(50.00 \%)$ & $6(42.86 \%)$ & $1(7.14 \%)$ & $0(0.00 \%)$ & 14 \\
OTHER & $14(41.18 \%)$ & $5(14.71 \%)$ & $14(41.18 \%)$ & $1(2.94 \%)$ & 34 \\
\hline
\end{tabular}

Table 4

Do You Want to Be an Active Learner if the Learning Environment Is Changing? (SOJUMP, 2014)

\begin{tabular}{llllll}
\hline $\mathrm{X} / \mathrm{Y}$ & Yes & No & Maybe & Nil & Total \\
\hline SHOU & $249(87.06 \%)$ & $5(1.75 \%)$ & $32(11.19 \%)$ & $0(0.00 \%)$ & 286 \\
UTAS & $11(78.57 \%)$ & $1(7.14 \%)$ & $2(14.29 \%)$ & $0(0.00 \%)$ & 14 \\
Other & $25(73.53 \%)$ & $1(2.94 \%)$ & $7(20.59 \%)$ & $1(2.94 \%)$ & 34 \\
\hline
\end{tabular}

Table 5

Which of the Following Statement That Best Describes Your Fear of Losing Face? (SOJUMP, 2014)

\begin{tabular}{|c|c|c|c|c|c|c|}
\hline $\mathrm{X} / \mathrm{Y}$ & $\begin{array}{l}\text { For fear of } \\
\text { confronting your } \\
\text { peers in public }\end{array}$ & $\begin{array}{l}\text { For fear of humiliating } \\
\text { others including your } \\
\text { opponents }\end{array}$ & $\begin{array}{l}\text { For fear of making } \\
\text { mistakes in front of } \\
\text { others }\end{array}$ & $\begin{array}{l}\text { For fear of lower social } \\
\text { standings found by your } \\
\text { peers }\end{array}$ & Nil & Total \\
\hline SHOU & $45(15.73 \%)$ & $30(10.49 \%)$ & $185(64.69 \%)$ & $24(8.39 \%)$ & 0 & 286 \\
\hline UTAS & $1(7.14 \%)$ & $3(21.43 \%)$ & $9(64.29 \%)$ & $1(7.14 \%)$ & 0 & 14 \\
\hline Other & $7(20.59 \%)$ & $5(14.71 \%)$ & $18(52.94 \%)$ & $3(8.82 \%)$ & 0 & 34 \\
\hline
\end{tabular}

Table 6

What Comment Will You Give on the Following?

\begin{tabular}{ll}
\hline Answers & Numbers of students \\
\hline Yes, definite it is showy. & 43 \\
I don't think I like to speak in front of other peers. & 33 \\
I am afraid of speaking in front of other students. & 12 \\
It is ok to ask questions in class but not voluntarily initiate a speech. & 2 \\
It is not showy at all. & 20 \\
\hline Note. Is "speaking or asking questions in class" regarded as "not modest" or "ostentatious"? 100 students from 2014 cohort \\
answered this supplementary question in an interview. See the table above.
\end{tabular}

